\title{
Gas Leak from Vinyl Taped Stainless Steel
} Dressing Jars

$$
\begin{array}{r}
\text { PEOENOD } \\
\text { AUS } 121999 \\
\text { OSTI }
\end{array}
$$

\section{Los Alamos \\ NATIONAL LABORATORY}

Los Alamos National Laboratory is operated by the University of California for the United States Department of Energy under contract W-7405-ENG-36. 
Edited by Nikki Goldman, Group CIC-1

An Affirmative Action/Equal Opportunity Enployer

This report was prepared as an account of work sponsored by an agency of the United States Government. Neither The Regents of the University of California, the United States

Government nor any agency thereof, nor any of their employees, makes any warranty, express or intplied, or assumes any legal liability or responsibility for the accuracy, completeness, or usefulness of any information, apparatus, product, or process disclosed, or represents that its use would not infringe privately owned rights. Reference herein to any specific commercial product, process, or service by trade name, trademark, manufacturer, or otherwise, does not necessarily constitute or imply its endorsement, recommendation, or favoring by The Regents of the University of Californin, the United States Government, or any agency thereof. The views and opinions of authors expressed herein do not necessarily state or reflect those of The Regents of the University of California, the United States Government, or any agency thereof. Los Alamos National Laboratory strongly supports academic freedom and a researcher's right to publish; as an institution, however, the Laboratory does not endorse the viewpoint of a publication or giarantee its technical correctness. 


\section{DISCLAIMER}

Portions of this document may be illegible in electronic image products. Images are produced from the best available original document. 
Gas Leak from Vinyl Taped Stainless Steel

Dressing Jars

Tim Hayes 


\title{
Gas Leak From Vinyl Taped Stainless Steel Dressing Jars
}

by

\author{
Tim Hayes
}

\begin{abstract}
The leak rates of nitrogen gas from stainless steel dressing jars taped with 2 inch vinyl tape were measured. These results were used to calculate hydrogen leak rates from the same jars. The calculations show that the maximum concentration of hydrogen buildup in this type of container configuration will be at least 3 orders of magnitude below the lower explosion limit for hydrogen in air.
\end{abstract}

Several months ago, the Waste Management and Environmental Compliance Group (NMT-7) requested that the leak rate of hydrogen gas from vinyl taped stainless steel dressing jars be determined quantitatively. This type of container is the typical configuration of the primary container for solid transuranic (TRU) waste at the Laboratory's Plutonium Facility at Technical Area 55 (TA-55). Usually the waste is placed in a stainless steel dressing jar with a loose fitting slip lid (Figure 1). The can is then taped by wrapping two inch vinyl tape around the lid (Figure 2). There are usually 2 complete continuous layers of tape around the circumference of the can to seal the seam and hold the lid in place. In some cases an additional layer of tape is applied to the lower seam formed by the first two layers of vinyl tape (Figure 3).

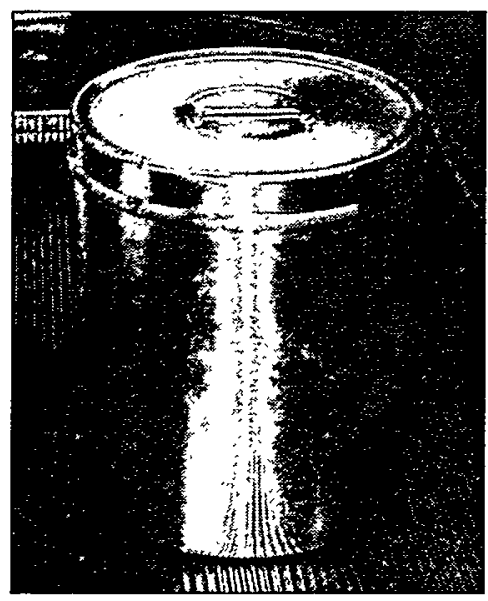

Figure 1. Stainless steel dressing jar.
The question posed is, if hydrogen is generated by radiolytic decomposition of the waste, will it leak from the taped container or build up to explosive limits? The results indicate that even at a high loading of 238$\mathrm{Pu}$ the hydrogen buildup in this type of container is 3 orders of magnitude below the explosion limit.

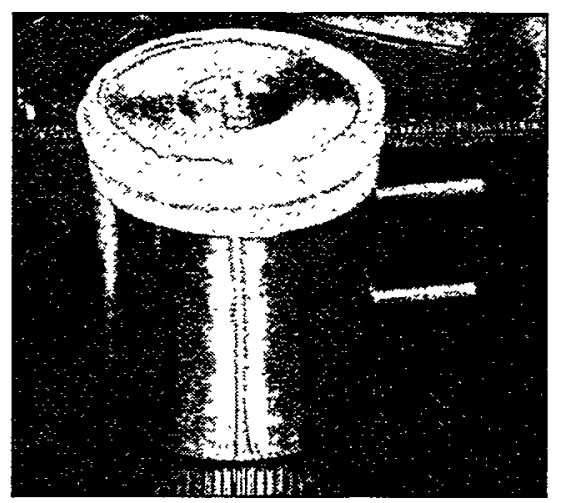

Figure 2. Dressing jar taped with 2 wraps of tape.

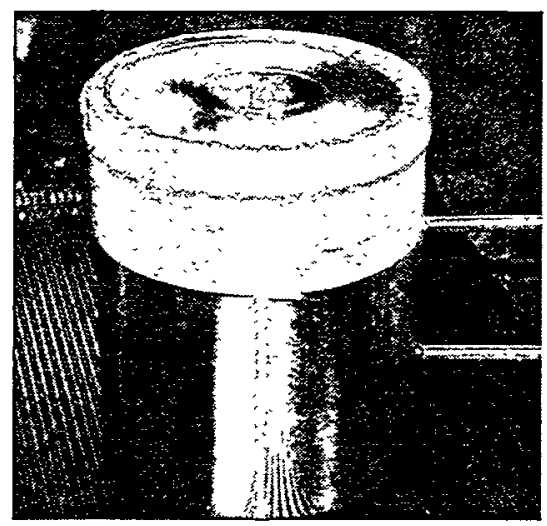

Figure 3. Dressing jar with additional tape. 


\section{Experimental Details}

A standard stainless steel dressing jar with a 7.125 inch diameter and an 8.375 inch height was modified by adding two 0.125 inch diameter pieces of tubing through the wall of the container (see Figure 4). The tubes were welded into place. A standard U-tube filled with water was used to measure pressure. A calibrated flowmeter was used for the flow test. The entire assembly was connected with Tygon tubing. For safety reasons, nitrogen instead of hydrogen was used to determine leak rates. All times were taken with a stopwatch. A schematic of the experimental arrangement is shown in Figure 5. Welds and connections were tested to ensure leak tightness. A standard barometer was used for atmospheric pressure readings. Each experiment was performed multiple times except where noted.

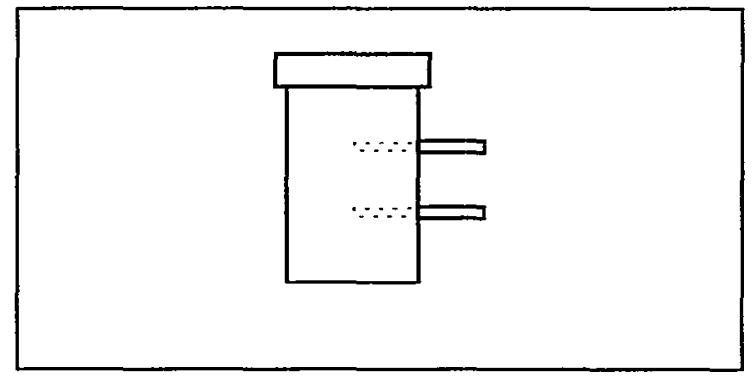

Figure 4. Stainless steel can with gas feed through.

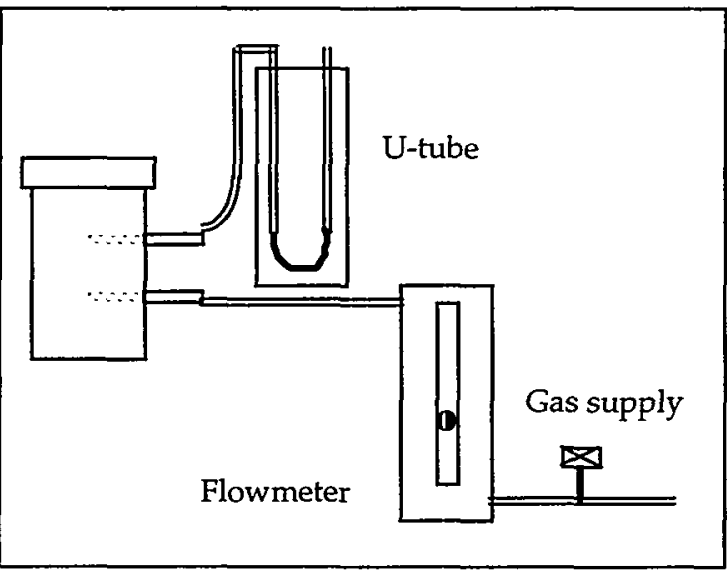

Figure 5. Experimental schematic.
The first experiment was to cross tape the lid of the dressing jar (Figure 6). This experiment was done to confirm that there is almost instantaneous gas loss when the dressing jar is taped in this manner.

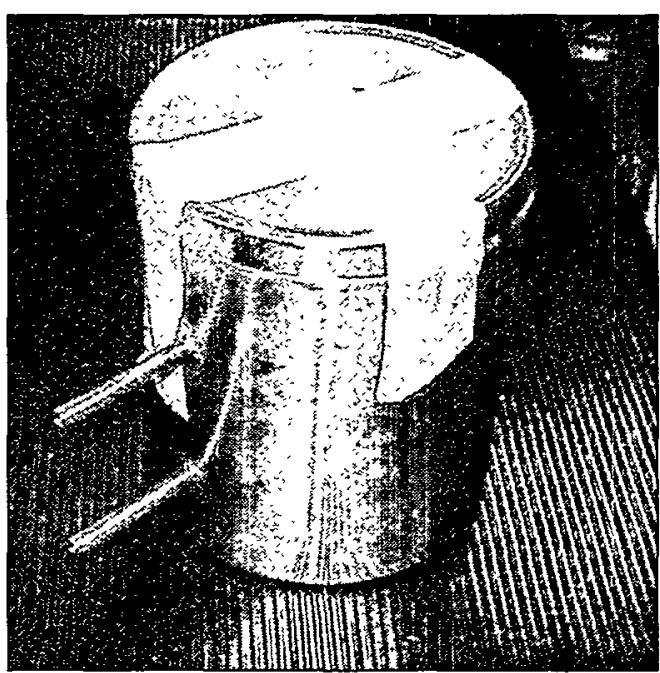

Figure 6. Cross taped dressing jar.

For the next set of experiments, the dressing jar was taped with 2 inch yellow vinyl tape with 2 full wraps around the circumference plus approximately 2 inches (Figure 2). The can was pressurized with nitrogen to constant pressure. The supply of nitrogen was turned off, and the loss of pressure as a function of time was recorded. This procedure was repeated with new tape for each trial. Because the leak rate was high for this kind of taping, a single experiment to determine the flow rate as a function of pressure was performed. The dressing jar was taped as described and pressurized to a constant pressure. The flow rate was measured. Measurements were taken at several different pressures.

Finally, a set of experiments was done to measure the loss of pressure as a function of time, but for these experiments an additional 2 layers of tape were added to the lower seam. The can was taped as described in the previous experiments, but the bottom seam of the vinyl tape was covered with an additional 2 full wraps around the circumference plus approximately 2 inches of vinyl tape (Figure 3). 


\section{Results}

For the cross-taped lid, a differential pressure of up to 10 inches of water was applied. When the gas supply was turned off, the can reached atmospheric pressure in less than $0.1 \mathrm{sec}$.

Figure 7 shows the pressure that could be maintained with a constant flow of gas to the dressing jar with the lid taped with 2 wraps of tape around the circumference (as shown in Figure 2).

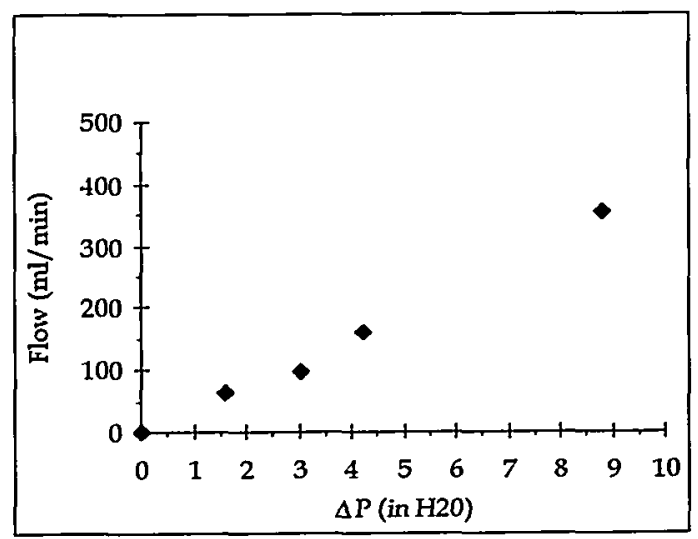

Figure 7. Flow needed to maintain a constant pressure.

For dressing jars taped with 2 wraps of tape around the circumference (as in Figure 2), the range of leak rates is shown in Figures 8 and 9 respectively. Note that the $y$-axis is the pressure above atmospheric pressure.

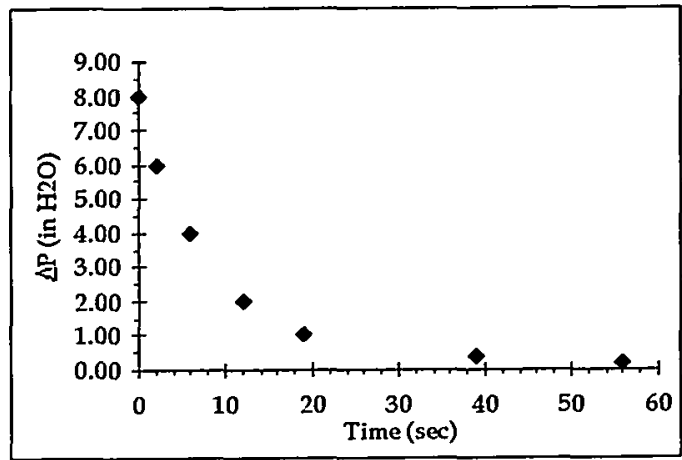

Figure 8. Fastest leak rate from a taped dressing jar.

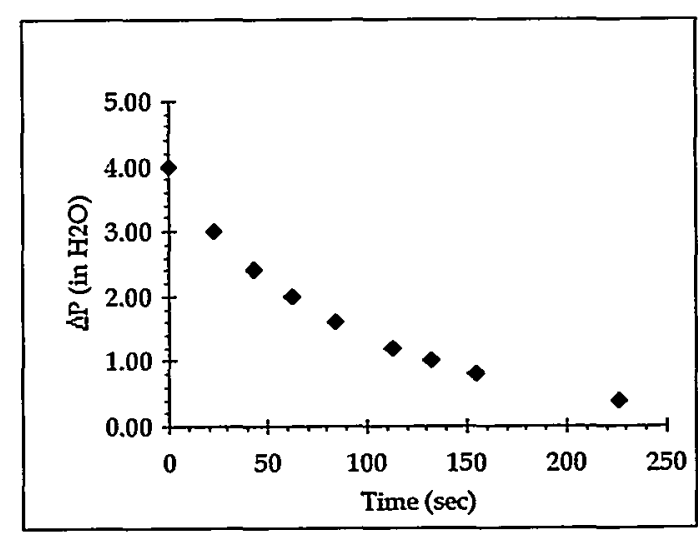

Figure 9. Slowest leak rate from a taped dressing jar.

When additional tape is added to the lower seam of the first set of vinyl tape, the leak rate slows. This method of taping made the leak rate more consistent. Figures 10 and 11 show typical data for the pressure loss as a function of time.

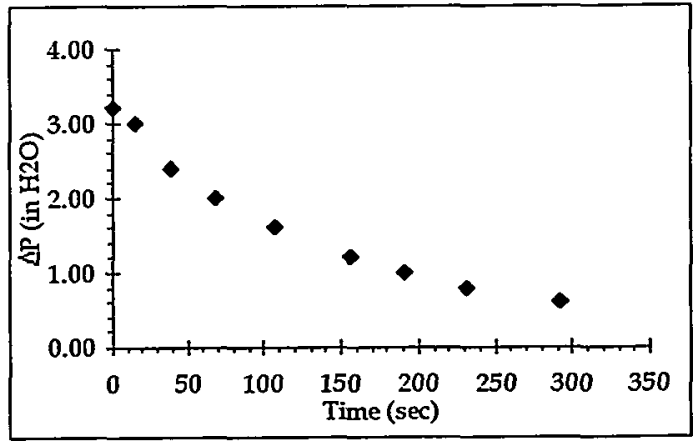

Figure 10. Leak rate with additional tape.

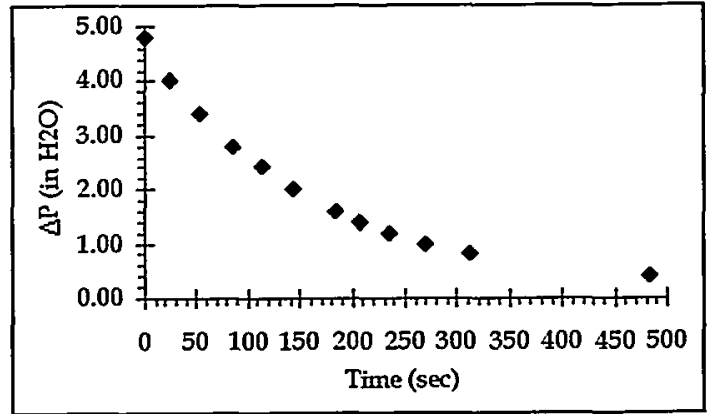

Figure 11. Leak rate with additional tape.

\section{Discussion}

Because of the speed at which the gas escaped from the container, it can be concluded that the primary escape path is through channels formed by wrinkles in the tape. Because the pressure differential is 
very low, only inches of water, I assumed that these channels would effectively act as simple holes in the container. If this is true, the kinetic theory of gases predicts that if the pressure inside the dressing jar is raised to a pressure $\triangle \mathrm{P}$ above the pressure outside the container, then the volume flow rate $\left(\Phi_{v}\right)$ of gas necessary to maintain this pressure is

$\Phi_{\mathrm{v}}=\Delta \mathrm{P} \frac{\mathrm{A}}{\mathrm{P}_{\mathrm{v}}} \sqrt{\frac{\mathrm{kT}}{2 \pi \mathrm{m}}}$,

where $A$ is the area of the hole in the jar, $P_{v}$ is the pressure at which the volume flow rate is determined, $\mathrm{k}$ is Boltzmann's constant, $\mathrm{T}$ is temperature, and $\mathrm{m}$ is the mass of the gas molecule. If this hypothesis is true the data in Figure 7 should plot as a straight line $\left(\Phi_{\mathrm{v}}=\mathrm{K} \Delta \mathrm{P}\right)$. This plot with the resulting line is shown in Figure 12.

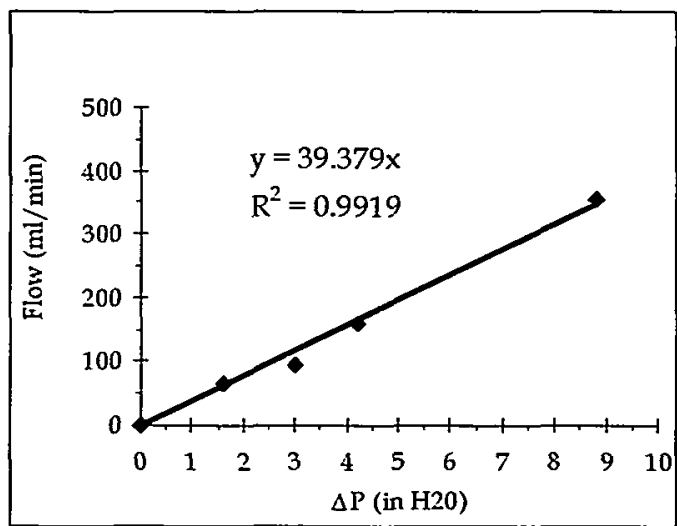

Figure 12. Linear fit of data from Figure 7.

Both the coefficient of determination ( $\left.\mathrm{R}^{2}\right)$ and the F-critical value test validate the linear relationship of the data. Using the formula for volume flow listed in Equation (1), the combined area of all the holes $(A)$ is $0.0159 \mathrm{~cm}^{2}$. A single circular hole of equivalent area has a diameter of $1.42 \mathrm{~mm}$. If the pressure inside the dressing jar is raised to a value of $\Delta P_{o}$ above the external pressure and then the gas supply is turned off, the time rate of change of the pressure predicted by the kinetic theory of gases is
$\Delta P=\Delta P_{o} e^{\left(-\frac{A t}{V} \sqrt{\frac{k T}{2 \pi m}}\right)}$

or

$\ln \frac{\Delta \mathrm{P}_{\mathrm{o}}}{\Delta \mathrm{P}}=\frac{\mathrm{At}}{\mathrm{V}} \sqrt{\frac{\mathrm{kT}}{2 \pi \mathrm{m}}}$

where $t$ is time and $V$ is the volume of the container. Equation (2) shows a plot of the logarithm of the ratio of the pressures verses time for Figures 8, 9, 10, and 11 should be linear. This is the case as shown in Figures 13, 14, 15, and 16 respectively.

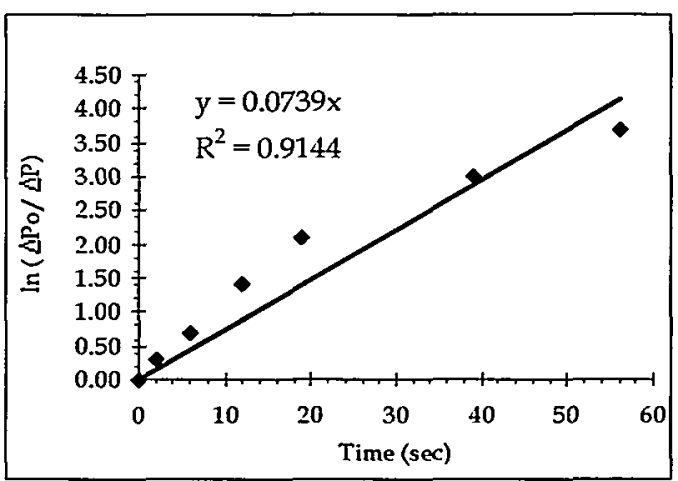

Figure 13. Linear fit of data from Figure 8.

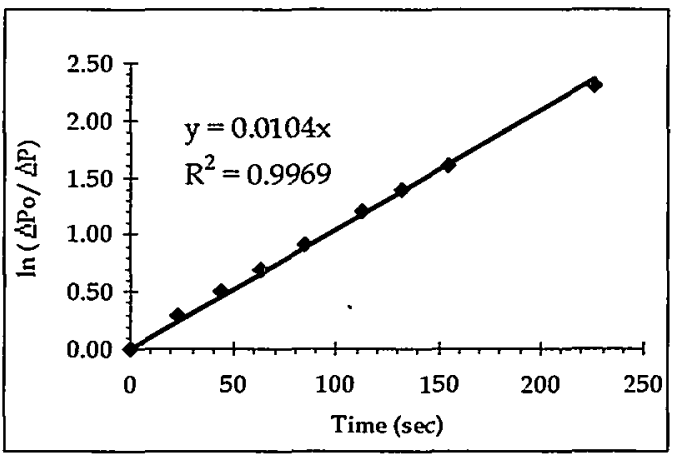

Figure 14. Linear fit of data from Figure 9. 


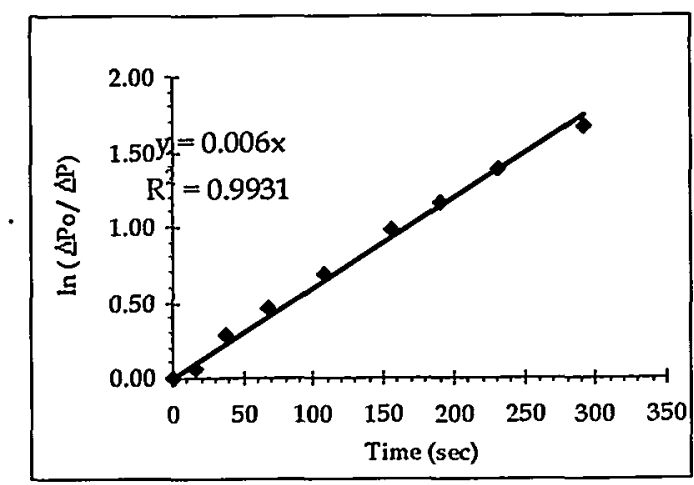

Figure 15. Linear fit of data from Figure 10.

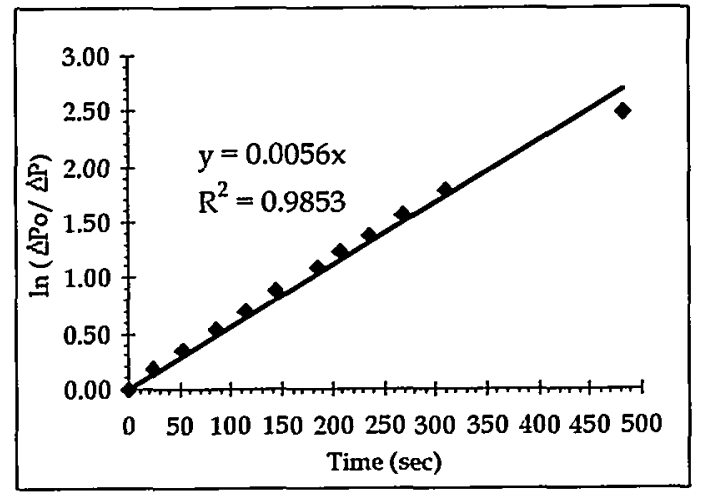

Figure 16. Linear fit of data from Figure 11.

Using Equation (2), the cumulative area of the leak can be calculated. Tabulated below are the results of these calculations. Note that in the last row of the table below I have included the results from the flow test (Figure 12) for comparison.

\begin{tabular}{|c|l|}
\hline $\begin{array}{c}\text { Figure } \\
\text { No. }\end{array}$ & Area $\left(\mathrm{cm}^{2}\right)$ \\
\hline 13 & 0.0241 \\
\hline 14 & 0.00339 \\
\hline 15 & 0.002 \\
\hline 16 & 0.0018 \\
\hline 12 & 0.0159 \\
\hline
\end{tabular}

With this information we can now relate this to hydrogen buildup in a taped can.

In the situation in which an item in a taped can is generating hydrogen by radiolysis, the hydrogen will rise to the top of the container and leak out of the channels in the tape. I will make several assumptions in the following analysis, which will overstate the amount of hydrogen that will build up in the dressing jar. The first assumption is that the hydrogen will mix perfectly with the air in the jar rather than rise to the top. This will simplify the mathematics greatly. The second assumption is that the combined area of the leak is $0.001 \mathrm{~cm}^{2}$. This is about half the area of the best taping job done in the experiments. I will also assume the hydrogen generation is constant over the life of the container. Furthermore, I will assume the atmospheric pressure will remain constant; this means that hydrogen cannot be pumped out or air pumped in because of atmospheric pressure changes.

With these assumptions, the steady-state percent by volume concentration of hydrogen in the container is given by

$$
\frac{\mathrm{V}_{\mathrm{H}_{2}}}{\mathrm{~V}} \times 100 \%=\frac{\mathrm{Q} \sqrt{2 \pi \mathrm{mkT}}}{\mathrm{AP}_{\mathrm{a}}} \times 100 \% ，
$$

where $\mathrm{VH}_{2}$ is the volume of hydrogen in the dressing jar, $V$ is the volume of the dressing jar, $Q$ is the rate at which hydrogen is generated, and $\mathrm{P}_{\mathrm{a}}$ the atmospheric pressure outside of the dressing jar. Using the area of $0.001 \mathrm{~cm}^{2}$, the rate $(Q)$ at which gas would have to be generated to reach the explosive limit for hydrogen in air, $4.00 \%$ by volume, is

$\mathrm{Q}=1.03 \times 10^{-4} \mathrm{~mole} \mathrm{H}_{2} /$ second.

In Los Alamos report LA-7674-MS, the gas generation rates from radiolytic attack of TRU contaminated hydrogenous waste was reported. The worst-case generation was from polyethylene contaminated with 238$\mathrm{Pu}$ at $0.55 \mathrm{Watt} / \mathrm{kg}(1.18 \mathrm{~g} 238-\mathrm{Pu} / \mathrm{kg})$. The rate at which hydrogen was generated was reported to be $13 \mathrm{mmol}$ per day per kilogram. This corresponds to a gas generation rate $(Q)$ of

$Q=1.5 \times 10^{-7}$ mole $\mathrm{H}_{2}$ per sec per $\mathrm{kg}$.

This hydrogen generation rate is 3 orders of magnitude below the rate needed to reach the explosion limit. If there is $1 \mathrm{~kg}$ of polyethylene waste contaminated with this level of 238-Pu, the steady-state hydrogen 
concentration would be $0.0058 \%$ by volume. This concentration is 690 times less than the lower explosion limit for hydrogen. Because of the assumptions behind the calculations, this value is overstated; the actual hydrogen concentration should be lower. Also keep in mind that the specific activity of 239-Pu is 283 times lower than the specific activity of 238-Pu.

\section{Conclusions}

It can be seen from the data presented that taping of cans is somewhat variable. However, even the best taping job allowed nitrogen gas to leak out at a rapid rate.

Relating this information to the lighter gas hydrogen shows that there should be at least several orders of magnitude safety margin with respect to the $4 \%$ lower explosion limit. 